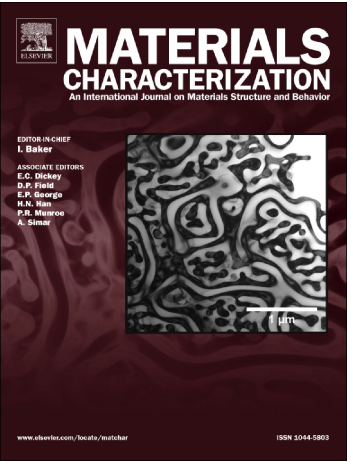

Residual stresses and microstructural evolution of ECAPed AA2017

L. Romero-Resendiz, I.A. Figueroa, C. Reyes-Ruiz, J.M. Cabrera, C. Braham, G. Gonzalez

PII: $\quad$ S1044-5803(18)32976-0

DOI: $\quad$ https://doi.org/10.1016/j.matchar.2019.04.007

Reference: $\quad$ MTL 9676

To appear in: $\quad$ Materials Characterization

Received date: $\quad 21$ October 2018

Revised date: $\quad 23$ February 2019

Accepted date: $\quad 4$ April 2019

Please cite this article as: L. Romero-Resendiz, I.A. Figueroa, C. Reyes-Ruiz, et al., Residual stresses and microstructural evolution of ECAPed AA2017, Materials Characterization, https://doi.org/10.1016/j.matchar.2019.04.007

This is a PDF file of an unedited manuscript that has been accepted for publication. As a service to our customers we are providing this early version of the manuscript. The manuscript will undergo copyediting, typesetting, and review of the resulting proof before it is published in its final form. Please note that during the production process errors may be discovered which could affect the content, and all legal disclaimers that apply to the journal pertain. 


\section{Residual stresses and microstructural evolution of ECAPed AA2017}

L. Romero-Resendiz ${ }^{\mathrm{a}}$, I. A. Figueroa ${ }^{\mathrm{a}}$, C. Reyes-Ruiz ${ }^{\mathrm{a}}$, J. M. Cabrera ${ }^{\mathrm{b}}$, C. Braham ${ }^{\mathrm{c}}$, G. Gonzalez ${ }^{\text {** }}$

a* Instituto de Investigaciones en Materiales, Universidad Nacional Autónoma de México, Circuito exterior S/N, Cd. Universitaria, A. P. 70-360, Coyoacán, C.P. 04510, Mexico

${ }^{\mathrm{b}}$ Departamento de Ciencia de los Materiales e Ingeniería Metalúrgica, ETSEIB Universidad Politécnica de Cataluña, Eduard Maristany 10-14, 08019 Barcelona, Spain c PIMM, UMR CNRS 8006, ENSAM, 151, boulevard de L'Hôpital 75013, Paris, France

* E-mail: joseggr@unam.mx

\section{Abstract}

The mechanical behavior and microstructural evolution of an AA2017 aluminum alloy processed by ECAP with an equivalent simple shear deformation of $\sim 6$ at $200^{\circ} \mathrm{C}$ were studied. Samples were characterized by means of scanning electron microscopy (SEM-EDSEBSD), image-assisted by focus ion beam (FIB), Vickers microhardness and X-ray diffraction (XRD) techniques. During the deformation process, the $\mathrm{Al}_{2} \mathrm{Cu}$ precipitates did not get fragmented or re-absorbed in the Al matrix. After the first ECAP pass, at least $50 \%$ of grains displayed an ultrafine size. The EBSD analysis showed an increment of the misorientation angle immediately after the first ECAP pass. The macrotexture evolution was explained in terms of the formation of $\mathrm{f} 1: A_{1}^{*}, \mathrm{~A}_{\theta}, \overline{\mathrm{A}}_{\theta}, A_{2 \theta}^{*}, \mathrm{f} 2: \mathrm{C}_{\theta}, \bar{B}_{\theta}, \mathrm{B}_{\theta}, \overline{\mathrm{A}}_{\theta}, \mathrm{A}_{\theta}, A_{1 \theta}^{*}$ and f3: $\mathrm{C}_{\theta}, \mathrm{B}_{\theta}, \bar{B}_{\theta}, \mathrm{A}_{\theta}, \overline{\mathrm{A}}_{\theta}, A_{2 \theta}^{*}$ fibers. The macro-residual stress measurements of the highly 
deformed samples showed linear $\sin ^{2} \psi$ profiles. The micro and macro-residual stresses were compatible with dislocation rearrangement, in which the annihilation and formation were in quasi-equilibrium. It was found that the highest microhardness value (1176 MPa) and grain refinement (at least $20 \%$ of grains showed a size smaller than $100 \mu \mathrm{m}^{2}$ ) appeared after the first extrusion pass. The decrease in hardness, after the second pass and the residual stress stability, could be associated to a dynamic recovery phenomenon.

\section{Keywords}

Al-alloy, ECAP, Texture, Residual stress, Dynamic recovery.

\section{Introduction}

One of the most recurrent techniques of severe plastic deformation for obtaining grain refinement and nanostructures is the equal channel angular pressing (ECAP) $[1,2]$. The importance of ECAP process is related to many factors such as the feasibility of implementation, the possibility of using the process in several alloys and the improvement of some mechanical properties without, significantly, deteriorating the thermal or electrical properties [3]. It is well known that important microstructural changes occur after the firsts ECAP passes, for instance, Iwahashi et. al. [5] reported a grain refinement from $1 \mathrm{~mm}$ to 4 $\mu \mathrm{m}$ with a single ECAP pass. However, the subsequent passes are necessary to achieve large grain misorientation angles $[6,7]$ and to improve the microstructural homogeneity of the alloy. It was also reported that the microstructure could vary on the highly deformed samples as a function of the processing route [8]. Other reports have identified that among the 
different processing routes, the route named $\mathrm{Bc}$, generates a greater homogeneity of crystalline orientations [9] and equiaxed microstructure in the extruded products $[10,11]$.

A number of aluminum (Al) alloys have been processed by ECAP, but specifically for the $2017 \mathrm{Al}$ alloy (AA2017), the number of reports are very scarce, even though this alloy is widely used in the automotive and aeronautical sectors (due to their high fracture toughness and corrosion resistance). Because of the cracking phenomenon that occurs at room temperature extrusion of this alloy [12], there is only one report that has succeeded in ECAPing the AA2017, but in an overaged condition $\left(350^{\circ} \mathrm{C}\right.$ for 1 hour), resulting in a decrease in hardness due to recrystallization [12]. In addition to the above-mentioned AA2017 report, other studies of Al-4 \%wt $\mathrm{Cu}$ alloys, deformed by ECAP, have been reported. These focused on the precipitates morphology after the ECAP process and the subsequent hardening [13-15].

Other Al-Cu based alloy compositions processed by ECAP have also been studied with the aim of reporting the fracture behavior, i.e the transformation of a brittle fracture to ductile mode [16-17]. For instance, the 2219, 2024 and 2014 alloys were ECAPed, and the effect of the process on 2219 alloy was reported in terms of the microstructural changes that can be subdivided into three stages: 1) an incubation period for new grain evolution, 2) grain fragmentation by frequent formation of deformation bands and 3) full development of new fine grains [18]. Besides, the results for the 2024 and 2014 alloys reported a considerable improvement in mechanical properties as a consequence of the ECAP passes [19-21]. 
Reports on the residual stress generated by ECAP are also rare. Previous results [22] showed that the residual stress values strongly depend on the inner or outer faces and the friction effects between the die-set and the sample in the study. On the other hand, there are some reports, in ECAPed Al alloys, related to texture analysis. For instance, El-Danaf reported the effect of extrusion die-angles on the texture after a single ECAP pass [23]. Similarly, Hoseini et al. compared different processing routes [24], indicating that the grain refinement effectiveness during ECAP depends on the die angle and the sample rotation between passes.

Due to the lack of information related to residual stresses, hardness and texture on this particular alloy, the objective of this work was to evaluate the ECAP effects on the microstructural evolution, including the grains morphology and size, precipitates and texture in an AA2017. The residual stresses and hardness profile as a measure of strain homogeneity were also assessed. This work introduces the measurement of near surface residual stresses in order to evaluate the importance of friction between the ECAP die and the sample.

\section{Experimental procedure}

Commercially available AA2017-T6 (Al-3.83Cu-0.62Mn-0.58Mg-0.55Si-0.51Fe-0.08Zn0.04Cr-0.04Ti-0.11 other, in wt $\%$ ) bars were used as starting material. The alloy was annealed at $400^{\circ} \mathrm{C}$ for $1 \mathrm{~h}$ and then furnace-cooled. The particular process was carried out in order to facilitate the extrusion by partial over-aging of the $\mathrm{Al}_{2} \mathrm{Cu}$ precipitates. A D2 steel die was used for the ECAP process. Samples with dimensions of $60 \mathrm{~mm}$ in length and $10 \mathrm{~mm}$ in diameter were used for the extrusion process at room temperature. The die has an inner angle of $\phi=90^{\circ}$, an outer curvature $\Psi=37^{\circ}$ and a channel diameter of $10 \mathrm{~mm}$. This die geometry 
generates a shear strain of $\sim 0.99$ for every ECAP pass, as previously reported [22]. The schematic representation of the experimental setup and the place where the samples were taken for the different characterization are shown in Fig. 1. It is worthy to note that the ECAP die set was placed inside an electrically heated furnace in order to keep a constant working temperature of $200^{\circ} \mathrm{C}$. The $\mathrm{Bc}$ route (rotation along its longitudinal axis by $90^{\circ}$ clockwise between each pass) was carried out. $\mathrm{MoS}_{2}$ lubricant was used for reducing the friction between the sample and the die walls.

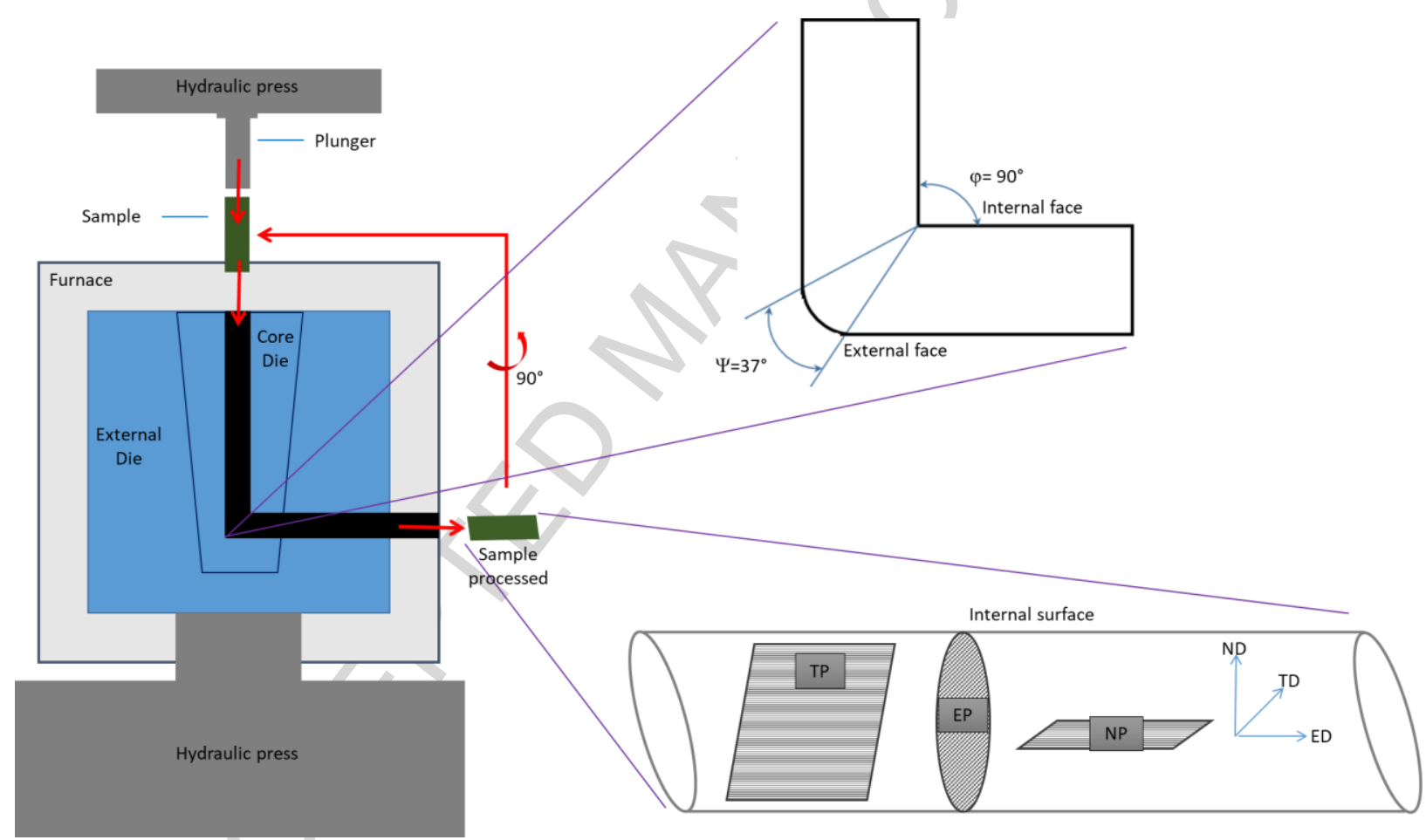

Fig. 1. Schematic representation of the ECAP system used in this study and planes where the samples were taken for the characterization. ND, TD and ED are the normal, transversal and extrusion directions, and TP, EP and NP are the transversal, extrusion and normal planes, respectively. 
The samples were identified as $0 \mathrm{P}, 1 \mathrm{P}, 2 \mathrm{P}, 3 \mathrm{P}, 4 \mathrm{P}, 5 \mathrm{P}$ and $6 \mathrm{P}$, where the prefix corresponds to the number of ECAP passes when completed. Previous to the microstructural examination, the surface of the samples was prepared, starting with SiC sandpaper of 800, 1200 and 2000, then diamond solutions of 0.3 and $0.1 \mu \mathrm{m}$ were used to obtain a mirror appearance. A Focus Ion Beam apparatus (model JEM-9320FIB) was used for metallographic observation, as conventional etching did not reveal the sub-grain microstructure in optical microscopy. Grain size observation was performed on the extrusion plane (EP - Fig. 1). The XRD measurements were performed using a Rigaku Ultima IV diffractometer, with $\mathrm{Cu}-\mathrm{K} \alpha$ radiation, crossbeam optics (CBO), $40 \mathrm{KV}$ and $44 \mathrm{~mA}$, with a step size of $0.02^{\circ}$ and a scanning speed of $0.07^{\circ}$ $\min ^{-1}$. For the texture analysis, Al pole figures of (111), (200) and (220) planes were obtained by employing a scanning range of $\alpha\left(0^{\circ}-90^{\circ}\right)$ and $\beta\left(0^{\circ}-360^{\circ}\right)$. The 3D Explore 2.5 software and MTEX (Matlab toolbox R2014b) were used for calculating the orientation distribution functions (ODF) and data displaying. For Electron Backscattering Diffraction (EBSD) the material was prepared using conventional metallographic preparation, then colloidal silica of $0.1 \mu \mathrm{m}$ for the final stage. Ultrasonic cleaning was used for removing surface impurities. The EBSD analysis was carried out with a Jeol 7600F scanning electron microscope (15 KV) with a Bruker Quantax EBSD detector.

The macro residual strains and stresses (type I) were evaluated on the internal surface (IS) (Fig. 1), using the $\sin ^{2} \psi$ method, in which the stress is calculated using the slope of the graph epsilon versus $\sin ^{2} \psi$ (where $\psi$ is the angle formed between the normal of the sample and the normal of the diffraction plane). The working (422) plane was used with at least 10 experimental $\psi$ values (from $-60^{\circ}$ to $54^{\circ}$ ). The macroresidual stresses were evaluated on the 
internal surface, without any surface preparation. This is important to retain the residual stresses produced during the process.

Microresidual strain (type II) was performed in the normal plane (NP) (Fig. 1). The microstrains $(\varepsilon)$ were evaluated using a Williamson-Hall plot based on the reflection peaks (111), (200), (220), (311), (222) and (400). Profile matching with a constant scale factor method (FullProf released 2017) was used for calculating the peak broadening. The instrumental peak width was calculated using a $\mathrm{LaB}_{6}$ standard powder. The working method assumes a Lorentzian XRD peak profile, within this approximation; it is possible to separate the strain $(\varepsilon)$ and crystallite size (D) effects from the integral breadth $(\beta)$ peak, following eq. (1):

$$
\frac{\beta \cos \theta}{\lambda}=\frac{1}{D}+4 \varepsilon\left(\frac{\sin \theta}{\lambda}\right)
$$

Although the Williamson-Hall model is merely qualitatively, it can evidence the tendency between the number of ECAP passes and the accumulated strain and/or crystallite size. The plot of $\frac{\beta \cos \theta}{\lambda}$ versus $\frac{2 \sin \theta}{\lambda}$ gives directly the crystallite size and the strain from the ordinate intersection and the slope of the linear fit of the experimental points. Within this approach, a slope closed to zero means that the strain is negligible, however, if the slope values are different from zero, they represent the strain contribution to the broadening [25].

A Shimadzu microdurometer model HMV-G was used for the microhardness measurements; the load was $100 \mathrm{~g}$ for $10 \mathrm{~s}$ on the normal plane (NP) (Fig. 1). A standard of medium-carbon steel was used for calibrating the microhardness tester. Taking into account that 55 measurements were taken per sample, the experimental error was calculated using the standard deviation. 


\section{Results and discussion}

In this study, the $\mathrm{Al}_{2} \mathrm{Cu}$ precipitates and the presence of $\mathrm{Mg}$ and $\mathrm{Si}$-rich compounds were observed as demonstrated in the micrographs obtained by SEM (Fig. 2a). From the EDS analysis (Fig. 2b), the black dots in the micrographs were identified as the $\mathrm{Mg}_{2} \mathrm{Si}$ phase, and the presence of these dots was mainly found at the center of $\mathrm{Al}_{2} \mathrm{Cu}$ precipitates. The $\mathrm{Mg}_{2} \mathrm{Si}$ precipitates were always observed independently of the degree of deformation applied. These precipitates have been seen in $\mathrm{Al}$ alloys with even lower contents of $\mathrm{Mg}$ and $\mathrm{Si}$ [26]. Fig. 2c shows the identified characteristic phases for $1 \mathrm{P}$ sample, similar results were also found for $0 \mathrm{P}$ and 6P samples. 
b)

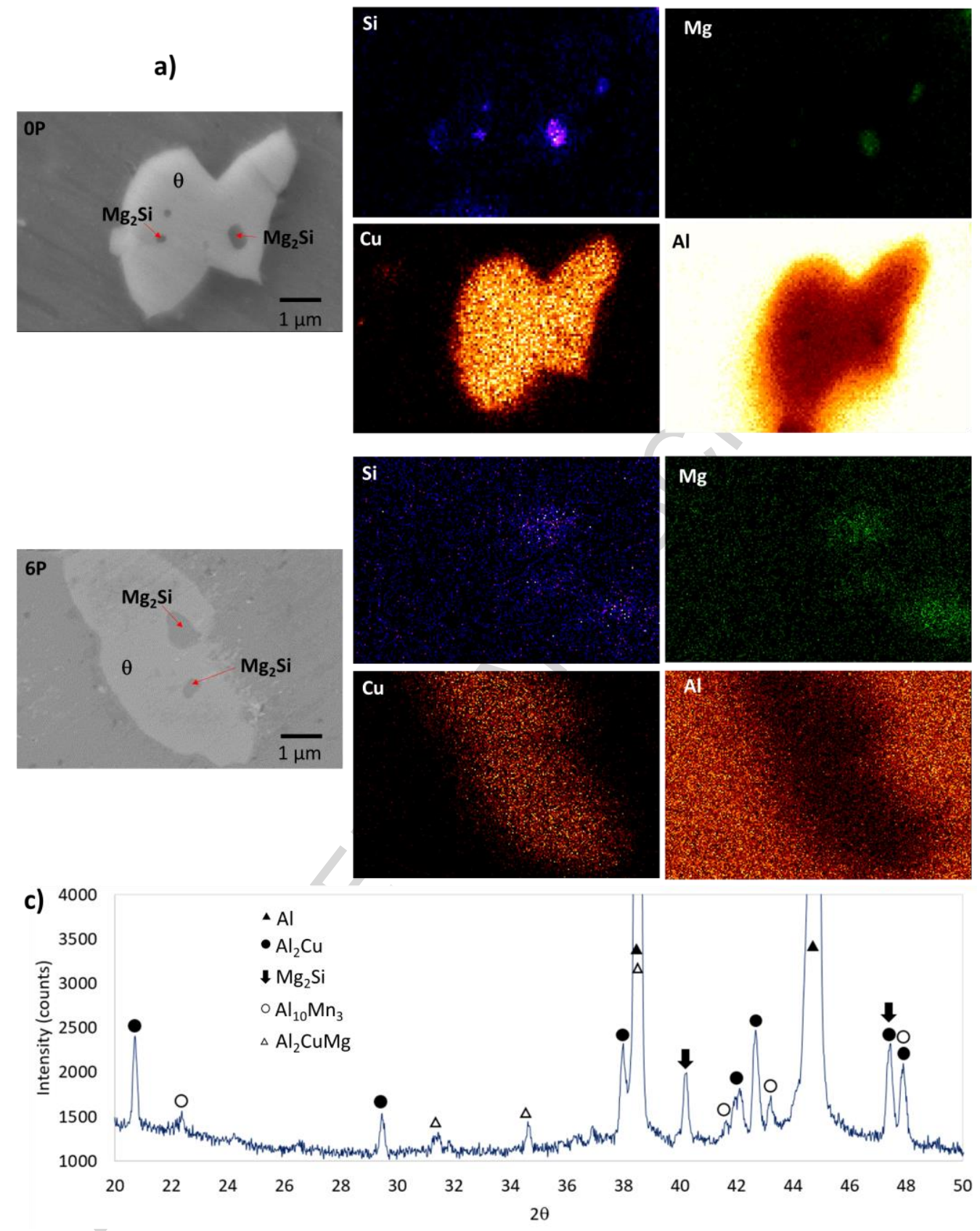

Fig. 2. a) SEM images of the ECAPed samples, indicating the presence of $\mathrm{Al}_{2} \mathrm{Cu}$ phase and $\mathrm{Mg}_{2} \mathrm{Si}$ precipitates for the initial condition (OP) and 6P sample, b) EDS mapping of $\mathrm{Al}_{2} \mathrm{Cu}$ and $\mathrm{Mg}_{2} \mathrm{Si}$ phases, c) X-ray diffractogram for the alloy studied. 
The presence of $\mathrm{Al}_{2} \mathrm{Cu}$ in $\mathrm{OP}, 1 \mathrm{P}$ and $6 \mathrm{P}$ passes was confirmed by $\mathrm{XRD}$, as shown in Fig 3 . The most intense peaks corresponded to $\mathrm{Al}$ and the weakest to the $\mathrm{Al}-\mathrm{Cu}$ phase. Complementary, further evaluation of grain morphology, misorientation and size were carried out for a better understanding of the microstructural evolution of this alloy.

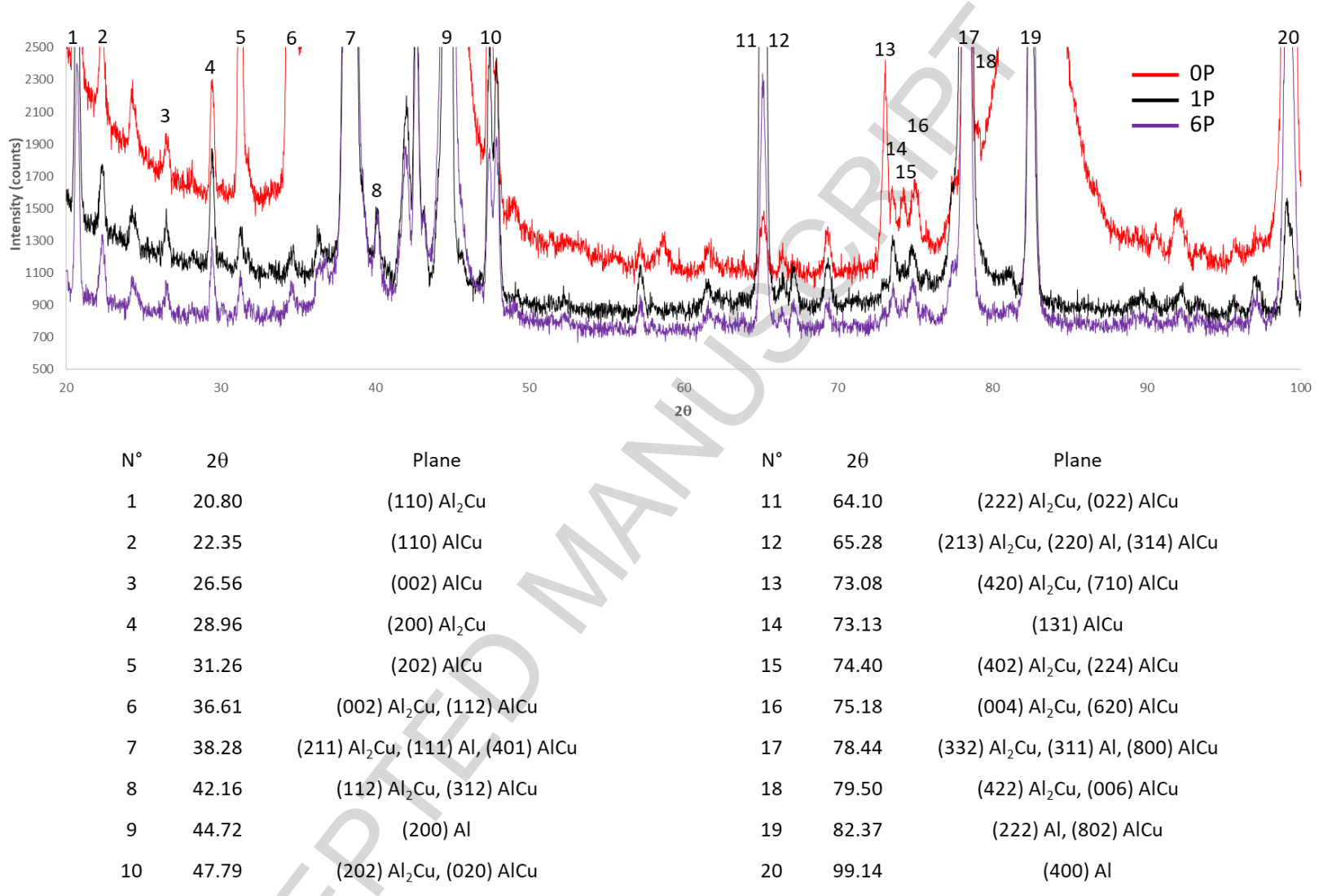

Fig. 3. XRD patterns for $0 \mathrm{P}, 1 \mathrm{P}$ and $6 \mathrm{P}$ samples.

The ECAP process generated a substantial grain refinement. Fig. 4 shows the corresponding micrographs for 0P, 1P, 5P, and 6P obtained by FIB. With this technique, the erosion of Ga ions on the sample surface generated an orientation contrast. For the last ECAP passes, it was possible to observe zones with weak contrast. It is though that these zones were produced due to the existence of dislocations tangles, where grain misorientation is less than $3^{\circ}$, 
coexisting with high angle grain boundary (HAGB). The grain refinement was clear, since the grain size dropped from $4 \mu \mathrm{m}$ for $0 \mathrm{P}$ to $0.3 \mu \mathrm{m}$ for $6 \mathrm{P}$.

Figure 5 shows the misorientation histogram of the highly deformed samples, for $1 \mathrm{P}$ and $6 \mathrm{P}$. For samples $1 \mathrm{P}$ to $6 \mathrm{P}$ the tendency for subgrains formation with low angle grain boundaries (LAGB) was observed. The subsequent formation of HAGB was also corroborated by electron backscattering diffraction (EBSD). The micrographs obtained by EBSD indicated substantial grain refinement after the first ECAP pass, producing ultrafine grain sizes, as expected for $\mathrm{Al}$ alloys processed by ECAP. It is worthy to note that after the $1 \mathrm{P}$ sample the grain refinement was rather small.
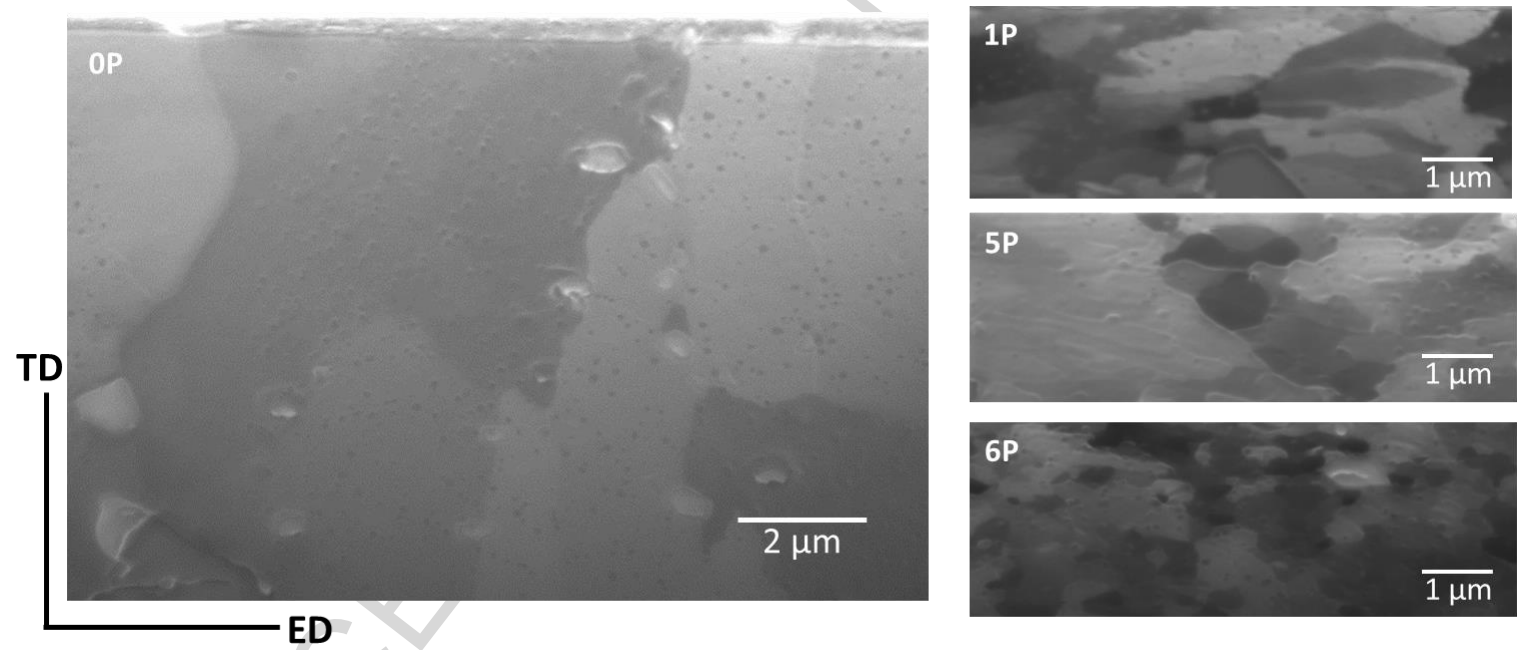

Fig. 4. Representative FIB images showing the microstructures for initial condition (OP), first, fifth and sixth ECAP passes (1P, 5P, and 6P respectively). For a better grain size statistics, the image for OP has been taken with less magnification. TD is transversal direction and ED extrusion direction. 
a)

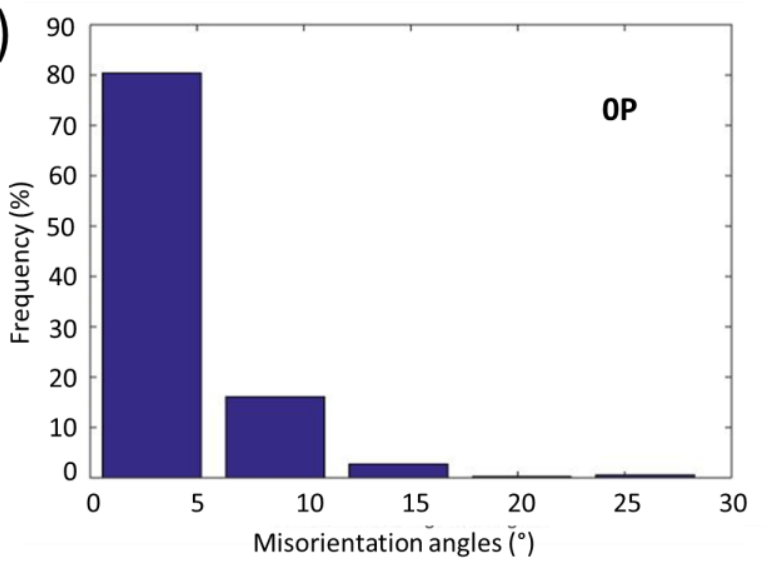

c)

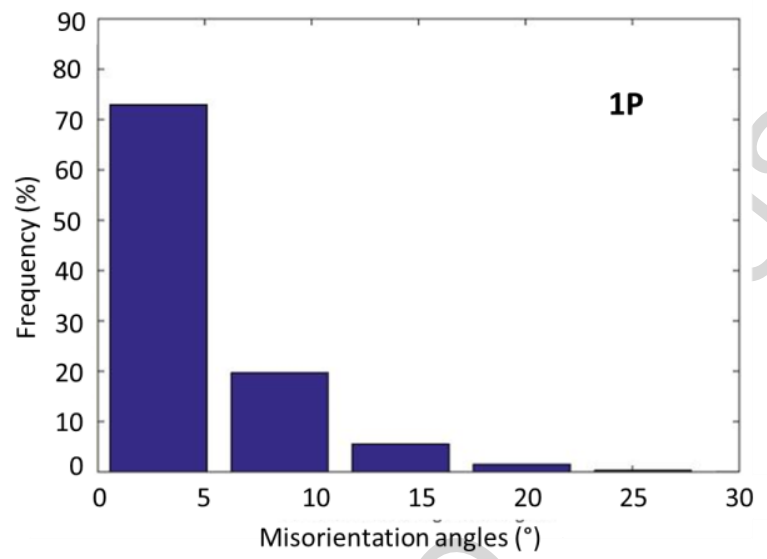

e)

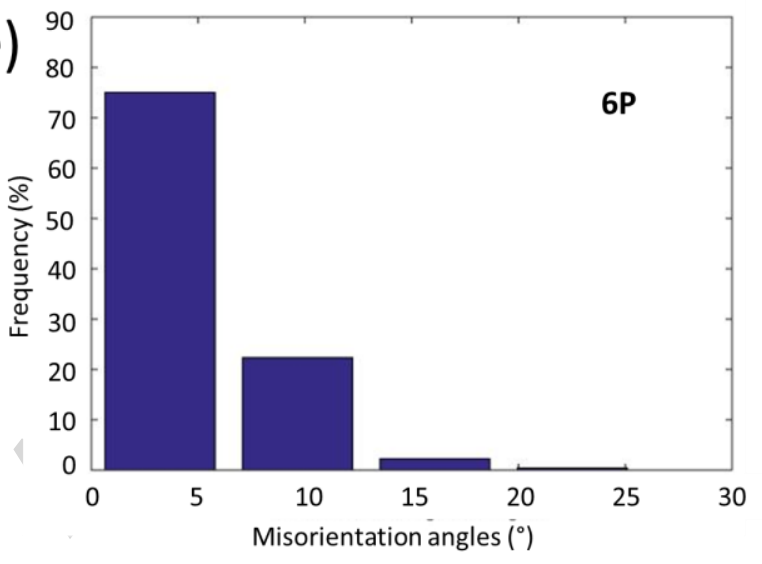

b)

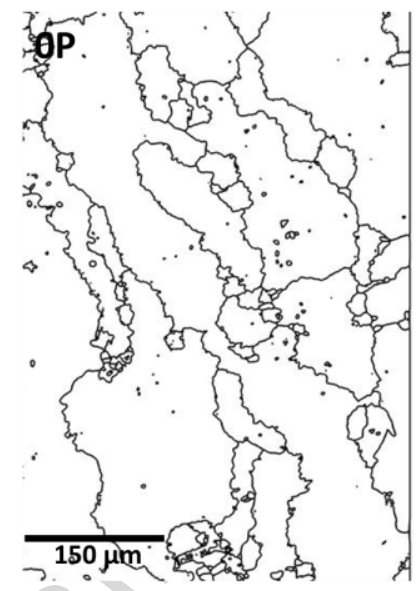

d)

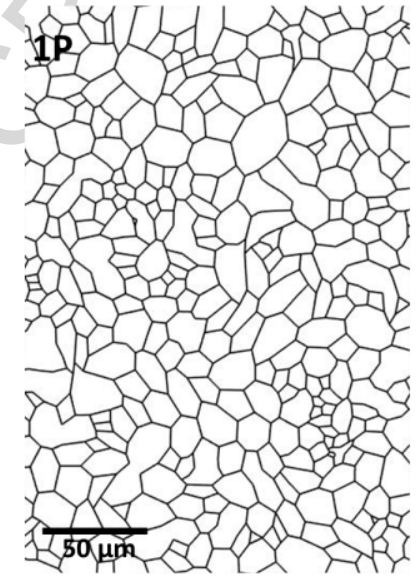

f)

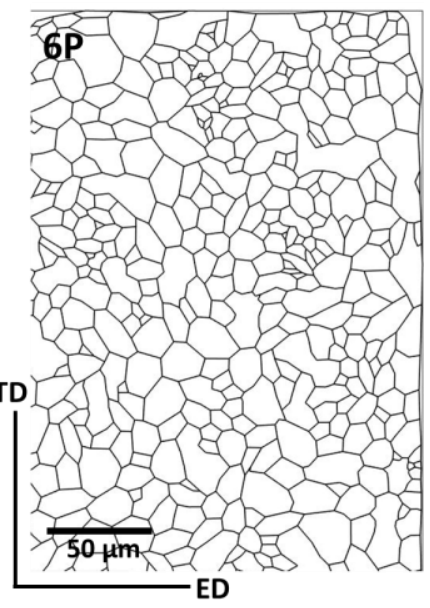

Fig. 5. EBSD results showing the misorientation histograms and micrographs for samples a-b) $0 P$, c-d) $1 P$, and e-f) $6 \mathrm{P}$, respectively. 
Fig. 6 shows the grain size histogram from $0 \mathrm{P}, 1 \mathrm{P}$, and $6 \mathrm{P}$ samples, assuming for the histogram calculation, an equivalent radius. According to the data obtained, and as already mentioned, the grain refinement was observed for the first ECAP pass. For the initial condition (0P), a grain area smaller than $10,000 \mu \mathrm{m}^{2}$, which corresponds to $30 \%$ of the studied zone, was determined. Similarly, for 1P and 6P samples, the results showed an area smaller than $100 \mu \mathrm{m}^{2}$, corresponding to $23 \%$ and $15 \%$, respectively. These results indicated a drop in grain size of two orders of magnitude. 

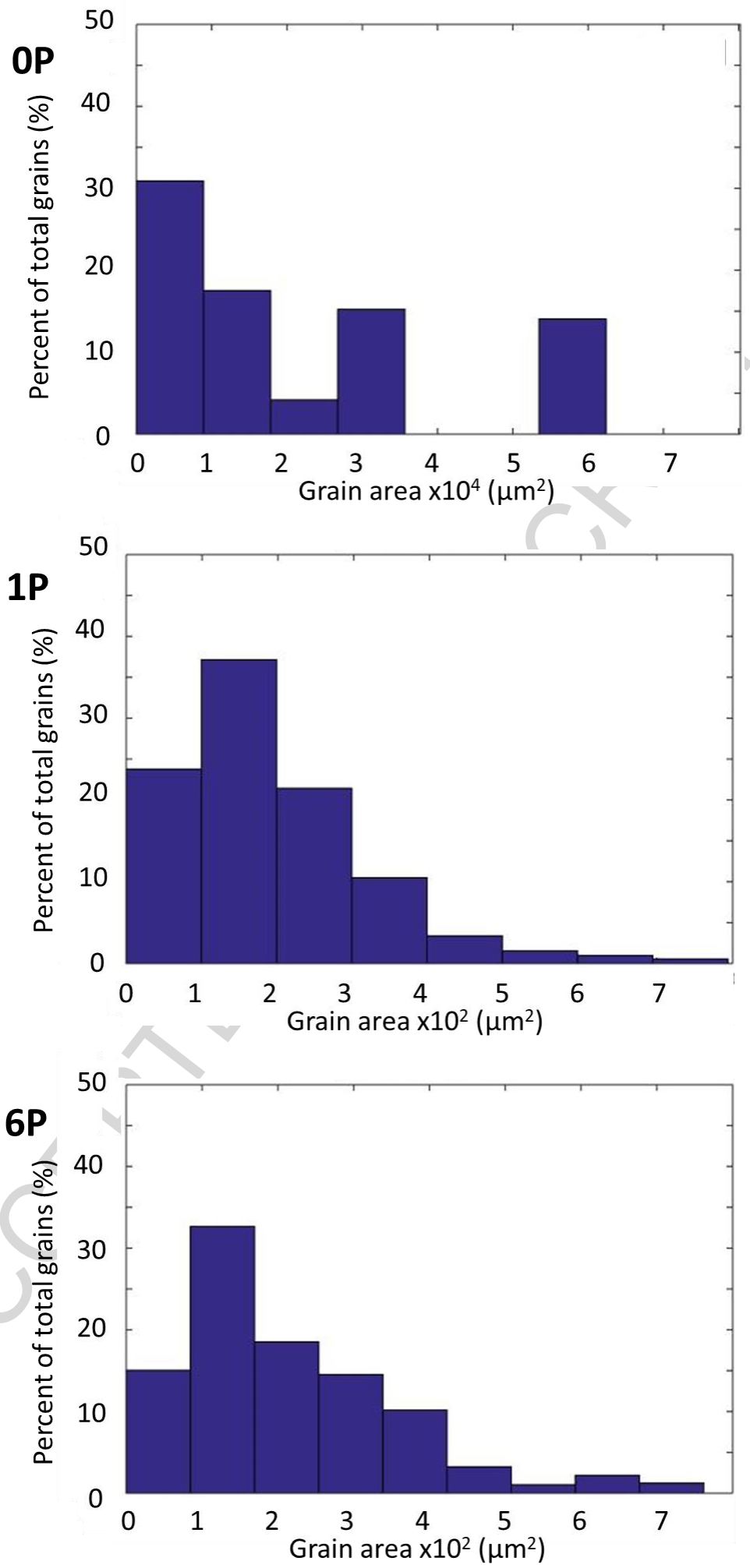

Fig. 6. Grain size distribution $0 \mathrm{P}, 1 \mathrm{P}$ and $6 \mathrm{P}$ samples. 
At this stage, it can be assumed that the success of the severe plastic deformation process reported in this work was due to the over-aging of the $\mathrm{Al}_{2} \mathrm{Cu}$ precipitates. As it will be explained later, the $\mathrm{Al}_{2} \mathrm{Cu}$ phase effect on the hardening process can be considered negligible. Thus, the ECAP hardening could be exclusively attributed to grain refinement [27]. Furthermore, the ECAP process did not generate any re-absorption of $\mathrm{Al}_{2} \mathrm{Cu}$ precipitates, but it cannot be denied that other precipitates could have partially disappeared during the process, although further investigation is highly pertinent to confirm this point. On the other hand, the increase of low angle grain boundaries could also be associated with the dislocation density, which was produced by the shear deformation process. The dislocation cells tended to accommodate in such fashion that produced high angle grain boundaries, as it has already been reported [28].

Another aspect for evaluating the microstructural change is the orientation or randomness of the processed grains. For this purpose, the analysis of the macrotexture evolution was performed in all samples, using the normal plane (NP), as illustrated in Fig. 1. The pole figures are shown in Fig. 7. At the initial condition (Fig.7-0P) two partial fibers were observed. They were designated as $\langle 110\rangle_{\theta}$ and $\{111\}_{\theta}$, respectively. An orientation along the $\langle 110\rangle_{\theta}$-fiber has a $\langle 110\rangle_{\theta}$-direction, which is counterclockwise rotated by $\theta=90^{\circ}$ from the ED, and orientation along the $\{111\}_{\theta}$-fiber has a $\{111\}$-plane counterclockwise rotated by $\theta$ from the ND-plane [29]. The 1P sample (Fig. 6-1P) showed five different texture components, identified as $A_{2 \theta}^{*}, A_{1 \theta}^{*}, \mathrm{C}_{\theta}, \mathrm{A}_{\theta}$ and $\overline{\mathrm{A}}_{\theta}$. These components are considered as the ideal ones for a simple shear process [30]. The pole figures for the $2 \mathrm{P}$ sample (Fig. 7-2P), showed the components $\mathrm{A}_{\theta}, A_{2 \theta}^{*}, \bar{B}_{\theta}$ and $\mathrm{B}_{\theta}$. The pole figures for the samples from $3 \mathrm{P}$ to $6 \mathrm{P}$ (Fig. 7-3P-6P) showed the disappearance of $\mathrm{A}_{\theta}$, whilst the $A_{2 \theta}^{*}, \bar{B}_{\theta}$ and $\mathrm{B}_{\theta}$ components 
displayed a decrement in intensity. The initial texture was strongly modified from the first to the third ECAP passes; however, it remained rather constant from the fourth to the sixth passes. Some shear components were found as expected, according to the literature [30]. Not all texture maxima on the PFs are described within the A, B, and C components of the simple shear texture. Kocks et al. mentioned that highly deformed metals might release some of the lattice strain through recovery, without changing the texture [31]. On the contrary, recrystallization might produce different texture in the new grains. Nevertheless, in this case, such recrystallization tended to be rather limited, as the process temperature was carried out at $200^{\circ} \mathrm{C}$. Fig. 8 shows the total volume fraction as function of ECAP passes. It was observed that the total volume fraction decrease monotonously as a function of ECAP passes. These results suggest that the new grains are, mainly, randomly orientated. 


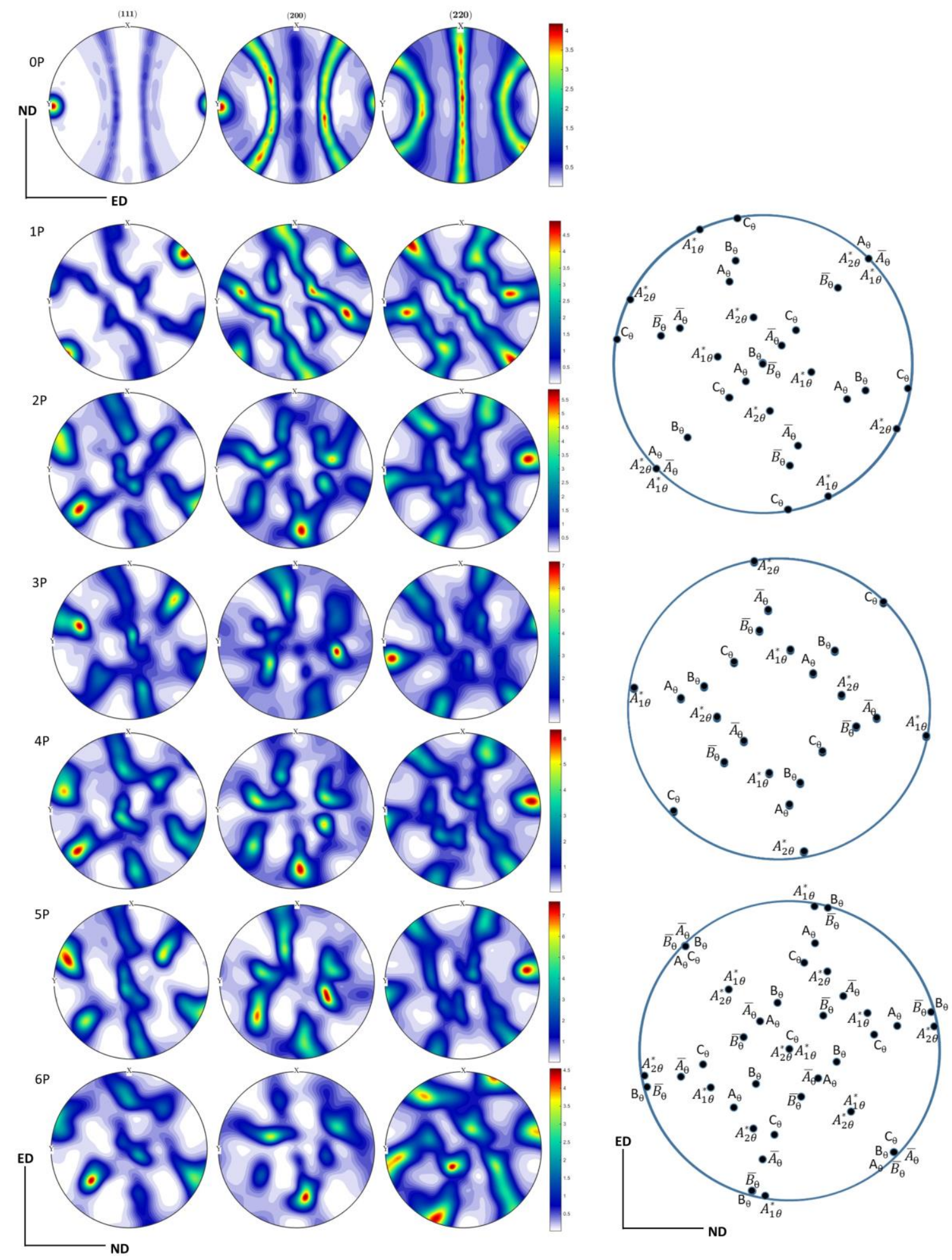

Fig. 7. Pole figures for samples $0 \mathrm{P}, 1 \mathrm{P}, 2 \mathrm{P}, 3 \mathrm{P}, 4 \mathrm{P}, 5 \mathrm{P}$ and $6 \mathrm{P}$ and key positions of ideal shear texture components for (111), (200) and (220) poles. 


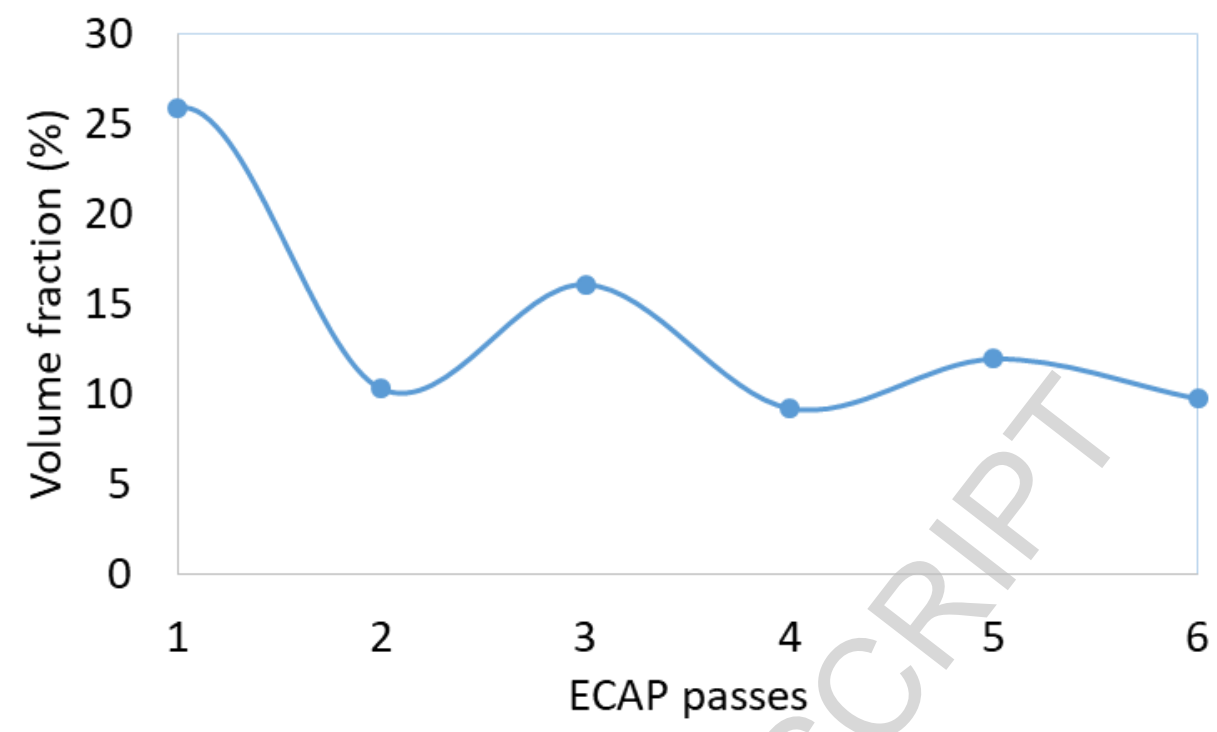

Fig 8. Total volume fraction of texture components as function of ECAP passes.

The orientation distribution functions (ODFs) were calculated for a complete study of the sample texture and are presented in Fig. 9. This figure confirms the presence of the aforementioned deformation components. From the same image, the presence of the following fibers was observed, being labeled as: $\left.\mathrm{f} 1=A_{1 \theta}^{*}-\mathrm{A}_{\theta} / \overline{\mathrm{A}}_{\theta}-A_{2 \theta}^{*}\{111\}\right\}_{\theta}, \mathrm{f} 2=\mathrm{C}_{\theta}$ passes through $\bar{B}_{\theta} / \mathrm{B}_{\theta}$ and $\overline{\mathrm{A}}_{\theta} / \mathrm{A}_{\theta}$ ending at $A_{1 \theta}^{*}$ and $\mathrm{f} 3=\mathrm{C}_{\theta}-\mathrm{B}_{\theta} / \bar{B}_{\theta}-\mathrm{A}_{\theta} / \overline{\mathrm{A}}_{\theta}<110>_{\theta}$ and $\mathrm{A}_{\theta} / \overline{\mathrm{A}}_{\theta}-$ $A_{2 \theta}^{*}\{111\}_{\theta}$ (symmetrical to the f2) [32]. The fibers intensity diminished after 3P sample for all fibers, showing a loss of symmetry intensity. 


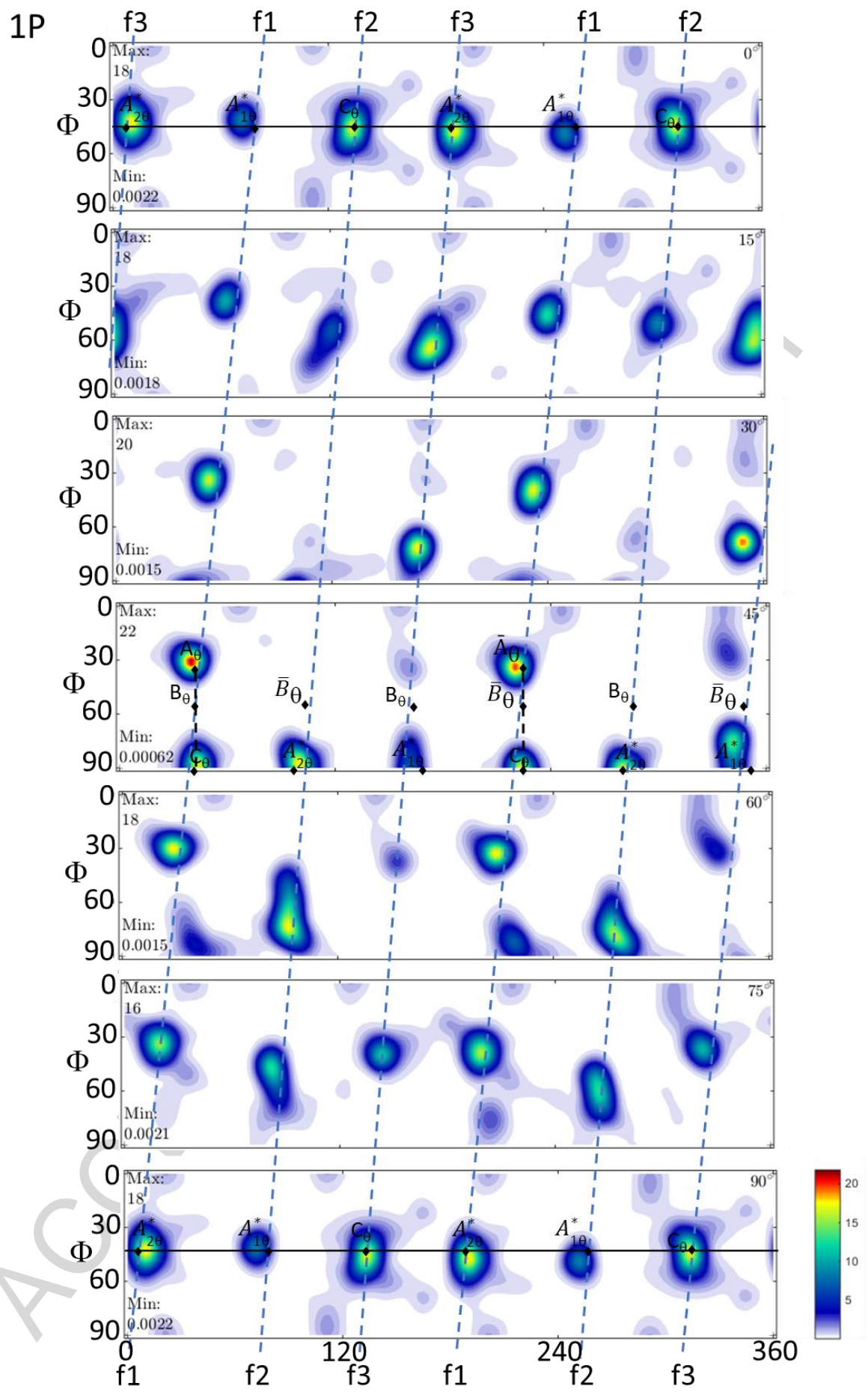




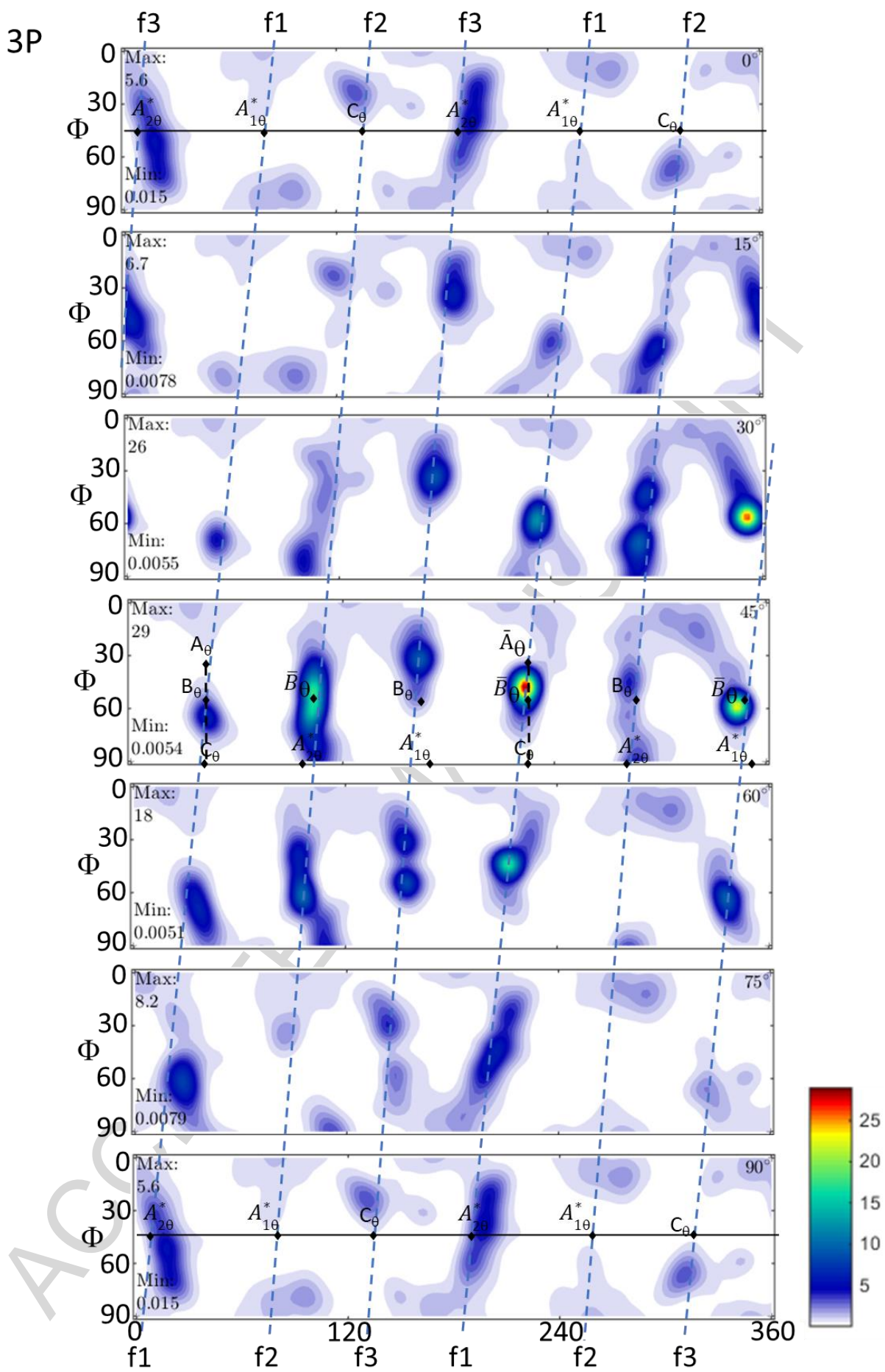




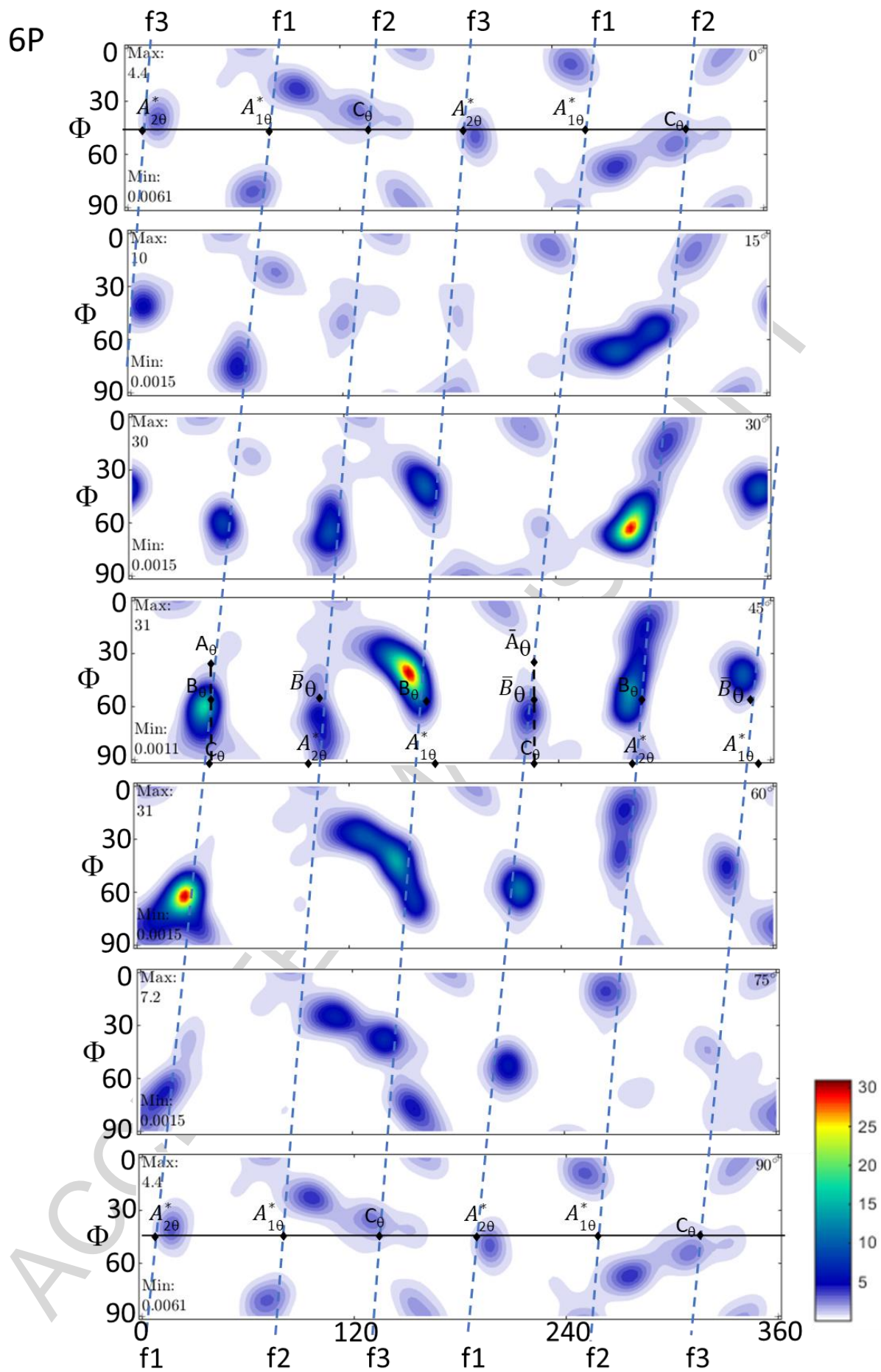

Fig. 9. Orientation Distribution Functions (ODFs) for 1P, 3P, and 6P samples. The evolution of fibers $\mathrm{f} 1, \mathrm{f} 2$ and $\mathrm{f} 3$ are shown as dotted lines. 
These results indicated the strong effect of the deformation mechanism of the ECAP process over the sample texture. However, it is also important to evaluate the effects of the mechanical process on the generated residual stresses. This has been attributed to the accumulative dislocation density, stored energy in the sample and heterogeneity of deformation process. The macro residual stress distribution profiles were obtained from the inner surface of the ECAPed samples, as shown in Fig. 10. For 0P, a linear profile almost horizontal or neutral in terms of stresses was observed, this was expected as all the starting samples were annealed and therefore any stress tends to be released. Sample 1P showed a linear profile with a positive slope that indicated a tensile stress behavior. A linear profile also denotes an alignment of main stresses with the sample axes (absence of $\sigma_{13}$ o $\sigma_{23}$ ). In the case of the last ECAP passes (after 3P), a compressive stress slope profile was obtained. The compressive stress slopes are strongly related to the size of the highly deformed layer that was produced due to friction effect between the die and the sample, during the ECAP process, as the size of this layer was proportional to the extrusion passes. 

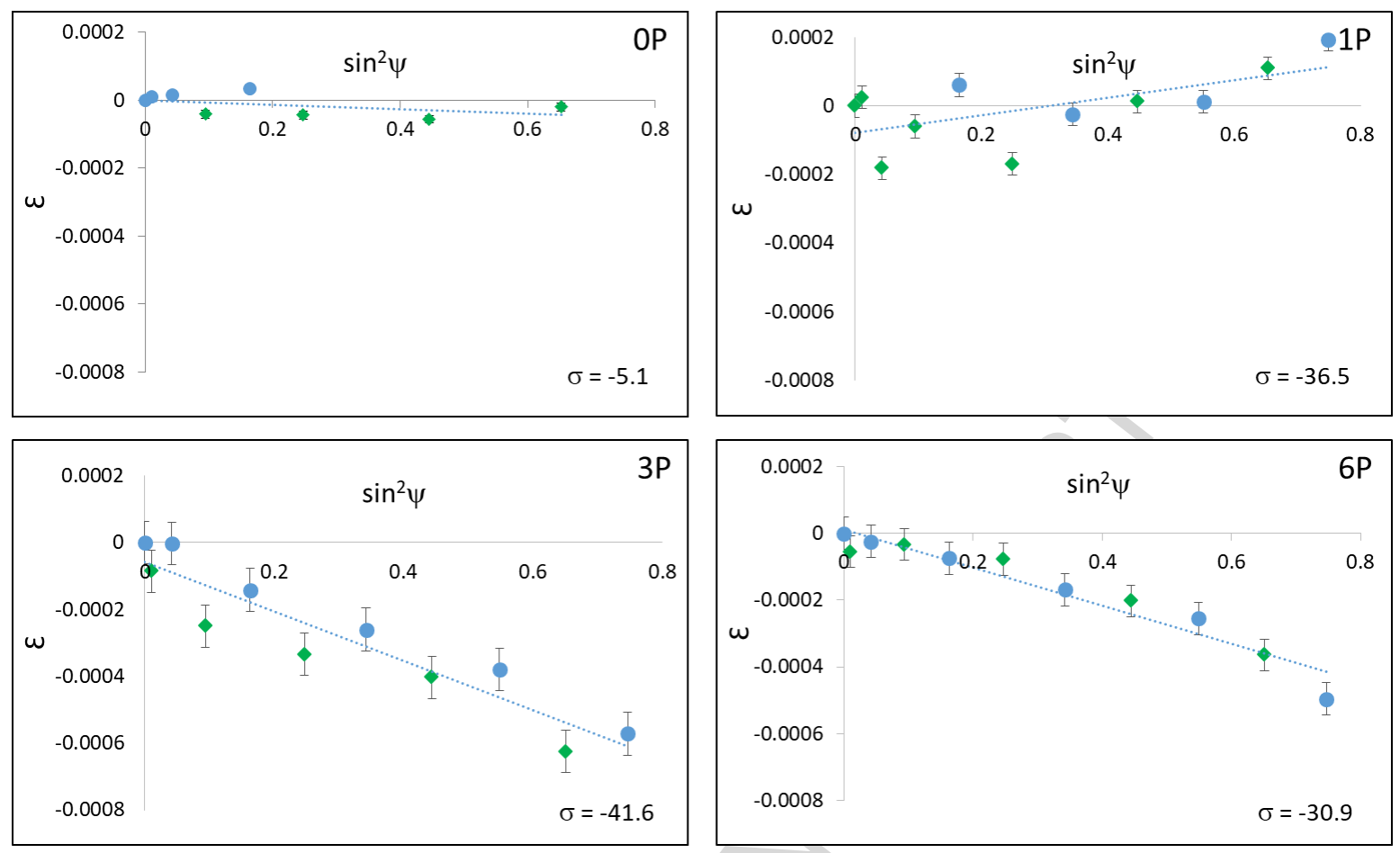

Fig. 10. Macro-residual stress profiles for $0 \mathrm{P}, 1 \mathrm{P}, 3 \mathrm{P}$ and $6 \mathrm{P}$ samples. The green dots correspond to $\psi(+)$ and the blue ones with $\psi(-)$ values.

Figure 11a displays the surface hardness for $0 \mathrm{P}$ and for $1 \mathrm{P}, 3 \mathrm{P}$ and $6 \mathrm{P}$. Fig. $11 \mathrm{~b}$ shows the residual stresses at the surface of the processed samples. Although there is no a correlation between the hardness and residuals stresses, in this particular case, the change in microhardness and the residual stresses showed, somehow, an asymmetric tendency, where both increased (in absolute values) as a function of the ECAP passes. The observed hardness drop, for samples $3 \mathrm{P}$ and $6 \mathrm{P}$, was attributed to the dynamic recovery that was originated for the temperature $\left(200^{\circ} \mathrm{C}\right)$ used in the ECAP process. 

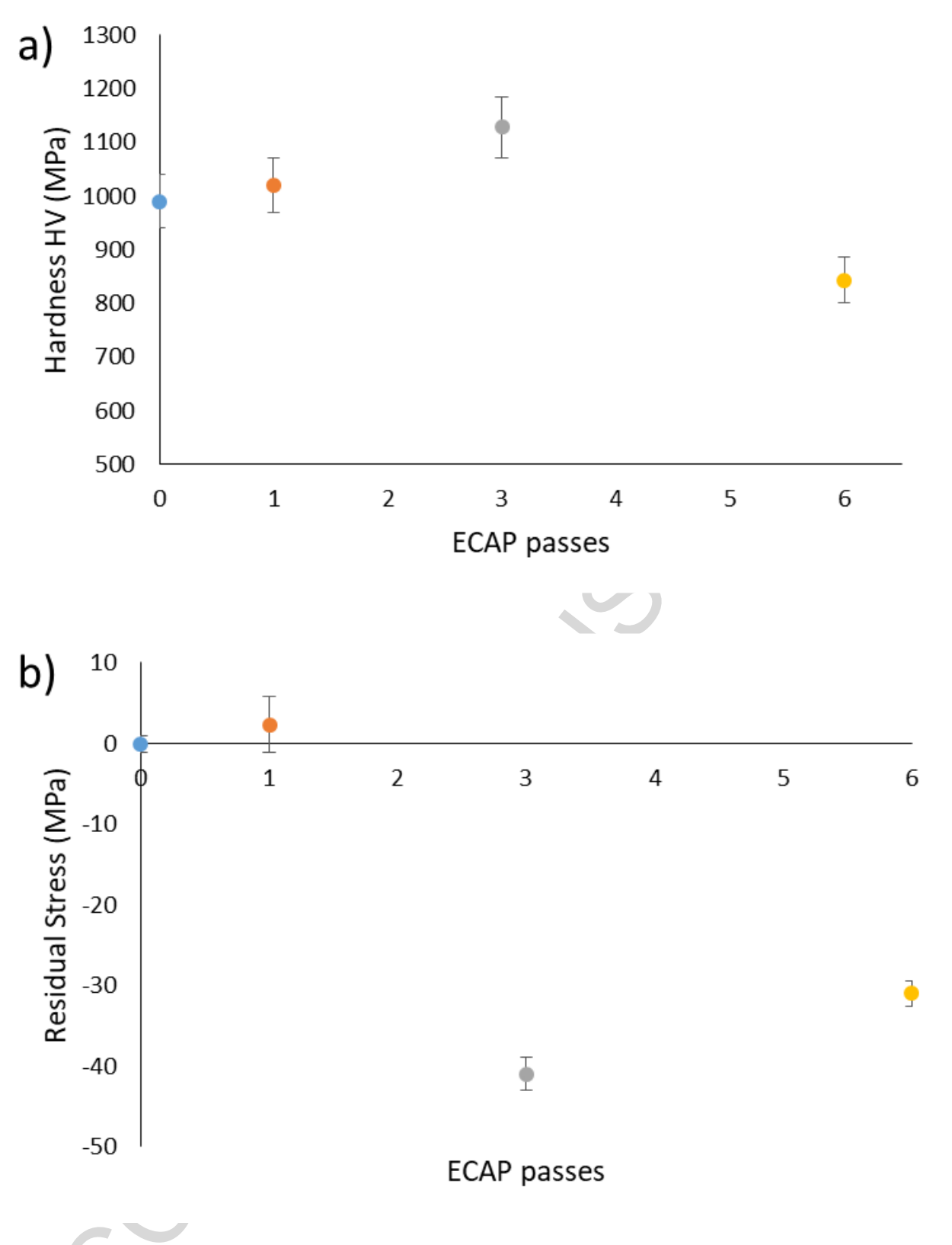

Fig. 11. a) Surface hardness and b) residual stresses vs ECAP passes.

The evolution-of the micro-strain was obtained by means of the Williamson-Hall plots (Fig. 12). From this figure, the slopes, which correspond to $2 \varepsilon$, increased as a function of ECAP passes. From the microstructural point of view, the ECAP process introduces a large number of dislocations. Therefore, it is anticipated an increment in the residual stress magnitude as a function of the number ECAP passes, however, such magnitude changed slightly for the last 
ECAP passes (3P-6P). This indicates that the process does influence a dislocation rearrangement. It is thought that this condition is due to the inherent nature of the recovery that is taking place at the present ECAP processing temperature.

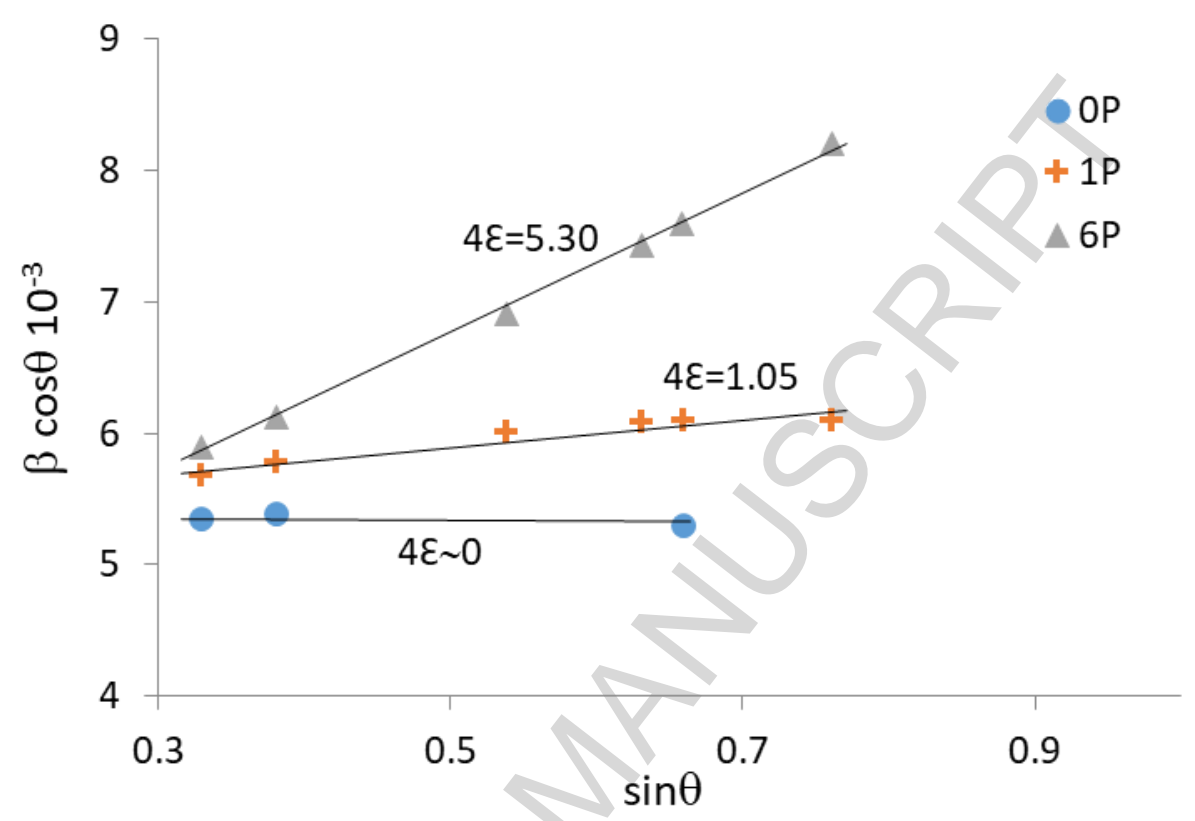

Fig. 12. Microstrain values for $0 \mathrm{P}, 1 \mathrm{P}$ and $6 \mathrm{P}$ samples.

Fig. 13a shows the Vickers microhardness measurements for $0 \mathrm{P}, 1 \mathrm{P}, 3 \mathrm{P}$ and $6 \mathrm{P}$ samples. In this figure, it was possible to evaluate the local hardness distribution from the internal to the external faces of the tested samples. The maximum hardness value was obtained for $1 \mathrm{P}$ sample $(1176 \pm 2 \mathrm{MPa})$, and then it dropped down to a rather constant value of $1081 \pm 2$ $\mathrm{MPa}$, for the subsequent passes. This tendency can be clearly observed in Fig. 13b, where the bulk microhardness values are plotted, exhibiting the same behavior. 

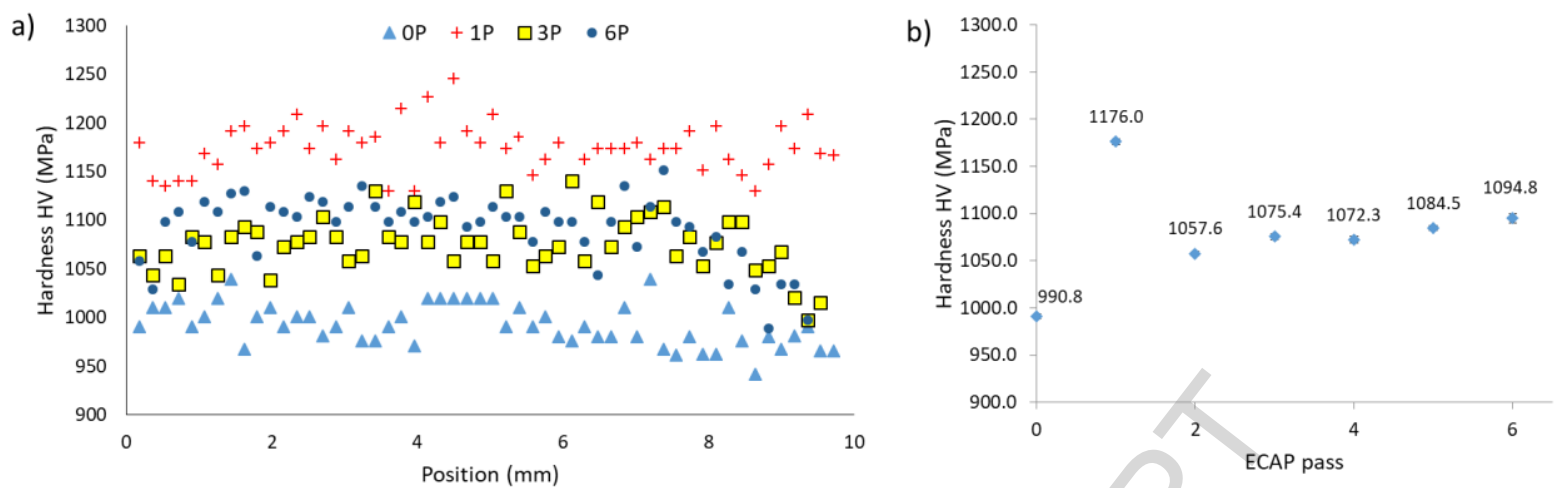

Fig. 13. Microhardness measurements a) line profile and b) bulk microhardness as a function of ECAP passes.

From the hardness evolution, the maxima and subsequent drop after 2 passes, could be explained in terms of partial dynamic recovery, as already stated. A similar phenomenon in an alloy of Al-1.7 at\% Cu processed by ECAP has been reported [33], being attributed to this phenomenon. Here, the organization of the dislocation tangles gives way to new ordered borders with few dislocations inside the grain.

The lack of softening in the first ECAP pass can be explained regarding the limited occurrence of diffusional processes [12]. It is well known that the diffusion is accelerated in SPD-processed metals due to the highly non-equilibrium grain boundaries [34] and internal stresses [35], therefore, it is necessary to increase the dislocation density, by work hardening, being generated after the first ECAP pass. Then, the sample extrusion temperature used in this study was high enough to accelerate the diffusive processes during the applied deformation in subsequent ECAP passes, as demonstrated in previous reports [36, 37]. Such phenomenon is more frequent in materials with a high stacking fault energy (SFE), as is the case for highly pure Al with an SFE reported in the literature of $\sim 160 \mathrm{~mJ} / \mathrm{m}^{2}[36,38]$. In addition to the drop in hardness for sample $2 \mathrm{P}$, the hardness values for the alloys with higher 
deformation passes are also congruent with the dynamic recovery process. These samples (2P to 6P) showed lower hardness values than those reported for similar compositions, after being subjected to the ECAP process $[39,20]$. The dynamic recovery effect of this system is not enough to avoid the formation of new grains in the last ECAP passes, as shown in Fig. 5. Here, the increment of grain misorientation angles indicates the possible dislocations rearrangement, generated during the ECAP process.

\section{Conclusions}

From the results obtained in this study, the following conclusions can be considered as the most important:

1) The grain refinement was evident from the first ECAP pass, where at least $20 \%$ of grains showed a size smaller than $100 \mu \mathrm{m}^{2}$. For $1 \mathrm{P}$ sample, $72 \%$ of low angle grain boundaries (LAGB) were observed, being the result of sub-grains formation due to the ECAP process.

2) The $\mathrm{Al}_{2} \mathrm{Cu}$ and $\mathrm{Mg}_{2} \mathrm{Si}$ precipitates did not change the morphology or size after the deformation process.

3) The formation of fibers $\mathrm{f} 1, \mathrm{f} 2$ and $\mathrm{f} 3$ were observed for all deformed samples.

4) The residual macro-stresses profile showed a neutral tendency for the initial condition, tensile behavior for $1 \mathrm{P}$ sample and compressive values from $3 \mathrm{P}$ to $6 \mathrm{P}$ samples. The maximum absolute value was obtained for the sample with 3 ECAP passes. This tendency is also congruent with the resultant surface hardness. 
5) The hardness profile from the internal to external faces showed an augmentation of hardness after the first ECAP pass. Subsequently, a drop from 1P to $2 \mathrm{P}$ was observed. For the subsequent passes, the hardness values exhibited a rather constant trend.

6) For the last ECAP passes, the resultant low grain refinement, the drop of macro-residual stresses and surface hardness are congruent with a dynamic recovery phenomenon. Similarly, the low percentage of HAGBs and the almost constant values hardness profile can also be associated with this phenomenon.

\section{Acknowledgments}

The authors would like to thank the funding support for this project by PAPIIT-UNAM [IN107917]. LR gratefully acknowledges the funding from scholarship CONACyT [592722]. Valuable technical support provided by A. Dutt, G. Lara, E. Hernández M., A. López-V., A. Tejeda, O. Novelo-Peralta, A. Amaro, J. Romero and C. Flores is also acknowledged.

\section{Data Availability Statement}

The raw data related to this manuscript would be made available on request.

\section{References}

[1] R.B. Figueiredo, T.G. Langdon, Fabricating ultrafine-grained materials through the application of severe plastic deformation: a review of developments in Brazil, J. Mater. Res. Technol. (2012) 55-62. https://doi.org/10.1016/S2238-7854(12)70010-8.

[2] R.Z. Valiev, R.K. Islamgaliev, I.V. Alexandrov, Bulk nanostructured materials from severe plastic deformation, Prog. Mater. Sci. 45 (2000) 103-189. https://doi.org/10.1016/S0079-6425(99)00007-9. 
[3] O.F. Higuera, J.M. Cabrera, Microstructure influencing physical and mechanical properties of electrolytic tough pitch copper produced by equal channel angular pressing, Mech. Mater. 67 (2013) 9-14. https://doi.org/10.1016/j.mechmat.2013.07.011.

[4] N.Q. Chinh, J. Gubicza, T. Czeppe, J. Lendvai, C. Xu, R.Z. Valiev, T.G. Langdon, Developing a strategy for the processing of age-hardenable alloys by ECAP at room temperature, Mater. Sci. Eng., A. 516 (2009) 248-252. https://doi.org/10.1016/j.msea.2009.03.049.

[5] Y. Iwahashi, Z. Horita, M. Nemoto, T.G. Langdon, An investigation of microstructural evolution during equal-channel angular pressing, Acta Mater. 45 (1997) 4733-4741. https://doi.org/10.1016/S1359-6454(97)00100-6.

[6] I. Mazurina, T. Sakai, H. Miura, O. Sitdikov, R. Kaibyshev, Effect of deformation temperature on microstructure evolution in aluminum alloy 2219 during hot ECAP, Mater. Sci. Eng., A. 486 (2008) 662-671. https://doi:10.1016/j.msea.2007.09.070.

[7] A. Golobororodko, O. Sitidikov, R. Kaibyshev, H. Miura, T. Sakai, Effect of pressing temperature on fine-grained structure formation in 7475 aluminum alloy during ECAP, Mater. Sci. Eng., A. 381 (2004) 121-128. https://doi:10.1016/j.msea.2004.04.049.

[8] Y. Iwahashi, Z. Horita, M. Nemoto, T.G. Langdon, Factors Influencing the Equilibrium Grain Size in Equal- Channel Angular Pressing: Role of Mg Additions to Aluminum, Metall. Mater. Trans. A. 29 (1998) 2503-2510. https://doi.org/10.1007/s11661-998$\underline{0222-\mathrm{y}}$.

[9] Y.G. Kim, Y.G. Ko, D.H. Shin, S. Lee, Effect of equal channel angular pressing routes on high-strain-rate deformation behavior of ultra-fine-grained aluminum alloy, Acta Mater. 58 (2010) 2545-2554. https://doi.org/10.1016/j.actamat.2009.12.041. 
[10] P. Venkatachalam, S.R. Kumar, B. Ravisankar, V.T. Paul, M. Vijayalakshmi, Effect of processing routes on microstructure and mechanical properties of $2014 \mathrm{Al}$ alloy processed by equal channel angular pressing, T. Nonferr. Metal. Soc. 20 (2010) 18221828. https://doi.org/10.1016/S1003-6326(09)60380-0.

[11] T.G. Langdon, M. Furukawa, M. Nemoto, Z. Horita, Using Equal-Channel Angular Pressing for Refining Grain Size, JOM. 52 (2000) 30-33. https://doi.org/10.1007/s11837-000-0128-7.

[12] M.A. Rekik, J. Masmoudi, S. Zghal, Y. Champion, N. Njah, Recovery of Industrial and Recycled Al-Cu Alloys Subjected to Severe Plastic Deformation, Phys. Procedia. 2 (2009) 1337-1342. https://doi.org/10.1016/j.phpro.2009.11.100.

[13] E.F. Prados, V.L. Sordi, M. Ferrante, The effect of $\mathrm{Al} 2 \mathrm{Cu}$ precipitates on the microstructural evolution, tensile strength, ductility and work-hardening behaviour of a Al-4 wt\% Cu alloy processed by equal-channel angular pressing, Acta Mater. 61 (2013) 115-125. https://doi.org/10.1016/j.actamat.2012.09.038.

[14] X. Xiao-Chang, L. Zhi-yi, L. Yun-tao, D. Peng, Z. Su-min, Evolution of precipitates of $\mathrm{Al}-\mathrm{Cu}$ alloy during equal-channel angular pressing at room temperature, T. Nonferr. Metal. Soc. 18 (2008) 1047-1052. https://doi.org/10.1016/S1003-6326(08)60179-X.

[15] Z. Liu, S. Bai, X. Zhou, Y. Gu, On strain-induced dissolution of $\theta^{\prime}$ and $\theta$ particles in Al-Cu binary alloy during equal channel angular pressing, Mater. Sci. Eng., A. 528 (2011) 2217-2222. https://doi.org/10.1016/j.msea.2010.12.060.

[16] M.I.A. El Aal, The effect of the pre-homogenization treatment on the fracture characteristics and wear properties of ECAPed Al-Cu alloys, Mater. Sci. Eng., A. 539 (2012) 308-323. https://doi.org/10.1016/j.msea.2012.01.101. 
[17] Z.F. Zhang, S.D. Wu, Y.J. Li, S.M. Liu, Z.G. Wang, Cyclic deformation and fatigue properties of $\mathrm{Al}-0.7 \mathrm{wt} \% \mathrm{Cu}$ alloy produced by equal channel angular pressing, Mater. Sci. Eng., A. 412 (2005) 279-286. https://doi.org/10.1016/j.msea.2005.08.221.

[18] I. Mazurina, T. Sakai, H. Miura, O. Sitdikov, R. Kaibyshev, Grain refinement in aluminum alloy 2219 during ECAP at $250^{\circ}$ C, Mater. Sci. Eng., A. 473 (2008) 297-305. https://doi:10.1016/j.msea.2007.04.112.

[19] W. J. Kim, C. S. Chung, D. S. Ma, S. I. Hong, H. K. Kim, Optimization of strength and ductility of $2024 \mathrm{Al}$ by equal channel angular pressing (ECAP) and post-ECAP aging, Scripta Mater. 49 (2003) 333-338. https://doi:10.1016/S1359-6462(03)00260-4.

[20] R. Kaibyshev, A. Mogucheva, Effect of ECAP on mechanical properties of an AA2014 alloy, Mater. Sci. Forum. 667-669 (2011) 931-936. https://doi:10.4028/www.scientific.net/MSF.667-669.931.

[21] P. Ventakatachalam, S. R. Kumar, B. Ravisankar, V. T. Paul, M. Vijayalakshmi, Effect of processing routes on microstructure and mechanical properties of $2014 \mathrm{Al}$ alloy processed by equal channel angular pressing, T. Nonferr. Metal. Soc. 20 (2010) 1822-1828. https://doi.org/10.1016/S1003-6326(09)60380-0.

[22] C. Reyes-Ruiz, I. A. Figueroa, C. Braham, J. M. Cabrera, O. Zanellato, S. Baiz, G. Gonzalez, Residual stress distribution of a 6061-T6 aluminum alloy under shear deformation, Mater. Sci. Eng. A. 670 (2016) 227-232. https://doi.org/10.1016/j.msea.2016.06.016

[23] E. A. El-Danaf, Mechanical properties, microstructure and texture of single pass equal channel angular pressed 1050, 5083, 6082 and 7010 aluminum alloys with different dies, Mater. Design. 32 (2011) 383-3853. https://doi.org/10.1016/j.matdes.2011.03.006 
[24] M. Hoseini, M. Meratian, M. R. Toroghinejad, J. A. Szpunara, Texture contribution in grain refinement effectiveness of different routes during ECAP, Mater. Sci. Eng. A. 497 (2008) 87-92. https://doi.org/10.1016/j.msea.2008.06.012

[25] G. Gonzalez, C. Braham, J.L. Lebrun, Y. Chastel, W. Seiler, I. Figueroa, Microstructure and texture of $\mathrm{Al}-2 \mathrm{Si}-\mathrm{xSn}(\mathrm{x}=0,4,8$ mass $\%)$ alloys processed by equal channel angular pressing, Mater. Trans., JIM. 53 (2012) 1234-1239. https://doi.org/10.2320/matertrans.M2012011.

[26] M. Cabibbo, E. Evangelista, A TEM study of the combined effect of severe plastic deformation and $(\mathrm{Zr}),(\mathrm{Sc}+\mathrm{Zr})$-containing dispersoids on an Al-Mg-Si alloy, J. Mater. Sci. 41 (2006) 5329-5338. https://doi:10.1007/s10853-006-0306-2.

[27] S.B. Kang, C.Y. Lim, H.W. Kim, J. Mao, Microstructure evolution and hardening behavior of 2024 aluminum alloy processed by the severe plastic deformation, Mater. Sci. Forum. 396-402 (2002) 1163-1168.

https://doi.org/10.4028/www.scientific.net/MSF.396-402.1163.

[28] C. Hernández, I. A. Figueroa, I. Alfonso, C. Braham, P. Castillo, G. González, Microstructure and Texture Evolution of the Al-20Sn Alloy Processed by EqualChannel Angular Pressing Using Route C, Mater. Trans. 56 (2015) 40-45. https://doi.org/10.2320/matertrans.M2014225

[29] S. Li, I.J. Beyerlein, M.A.M. Bourke, Texture formation during equal channel angular extrusion of fcc and bcc materials: comparison with simple shear, Mater. Sci. Eng., A. 394 (2005) 66-77. https://doi.org/10.1016/j.msea.2004.11.032.

[30] S. Li, I.J. Beyerlein, D.J. Alexander, S.C. Vogel, Texture evolution during multipass equal channel angular extrusion of copper: Neutron diffraction characterization 
and polycrystal modeling, Acta Mater. 53 (2005) 2111-2125.

https://doi.org/10.1016/j.actamat.2005.01.023.

[31] U. F. Kocks, C. N. Tomé, H. -R. Wenk, A. J. Beaudoin, Preferred Orientations in Polycrystals and Their Effect on Materials Properties, Cambridge University Press (2000) $676 \mathrm{pp}$.

[32] I.J. Beyerlein, L.S. Tóth, Texture evolution in equal-channel angular extrusion, Prog. Mater. Sci. 54 (2009) 427-510. https://doi.org/10.1016/j.pmatsci.2009.01.001.

[33] M. Murayama, Z. Horita, K. Hono, Microstructure of two-phase Al-1.7 at\% Cu alloy deformed by equal-channel angular pressing, Acta Mater. 49 (2001) 21-29. https://doi.org/10.1016/S1359-6454(00)00308-6.

[34] R.Z. Valiev, T.G. Langdon, Principles of equal-channel angular pressing as a processing tool for grain refinement, Prog. Mater. Sci. 51 (2006) 881-981. https://doi.org/10.1016/j.pmatsci.2006.02.003.

[35] Bachmaier, M. Hafok, R. Pippan, Rate independent and rate dependent structural evolution during severe plastic deformation, Mater. Trans., JIM. 51 (2010) 8-13. https://doi.org/10.2320/matertrans.MB200912.

[36] F. Liu, H. Yuan, J. Yin, J.T. Wang, Influence of stacking fault energy and temperature on microstructures and mechanical properties of fcc pure metals processed by equal-channel angular pressing, Mater. Sci. Eng., A. 662 (2016) 578-587. https://doi.org/10.1016/j.msea.2016.03.022.

[37] N.Q. Chinh, P. Szommer, Z. Horita, T.G. Langdon, Experimental evidence for grain-boundary sliding in ultrafine-grained aluminum processed by severe plastic deformation, Adv. Mater. 18 (2006) 34-39. https://doi.org/10.1002/adma.200501232. 
[38] S. Xue, W. Kuo, Q. Li, Z. Fan, J. Ding, R. Su, H. Wang, X. Zhang, Texture-directed twin formation propensity in $\mathrm{Al}$ with high stacking fault energy, Acta Mater. 144 (2018) 226-234. https://doi.org/10.1016/j.actamat.2017.10.053.

[39] M.I.A. El Aal, N.E. Mahallawy, F.A. Shehata, M.A. El Hameed, E.Y. Yoon, H.S. Kim, Wear properties of ECAP-processed ultrafine grained Al-Cu alloys, Mater. Sci. Eng., A. 527 (2010) 3726-3732. https://doi.org/10.1016/j.msea.2010.03.057. 
Highlights

- The micro-strain increased considerably between the first and the sixth ECAP passes.

- Dynamic recovery occurred after the first extrusion pass

- Texture and residual stress explained in terms of shear stress phenomenon.

- Hardening mechanism described related to grain refinement and dislocation density. 